\title{
Long-term Safety and Efficacy of Latanoprostene Bunod 0.024\% in Japanese Subjects with Open-Angle Glaucoma or Ocular Hypertension: The JUPITER Study
}

\author{
Kazuhide Kawase · Jason L. Vittitow $\cdot$ Robert N. Weinreb • \\ Makoto Araie · For the JUPITER Study Group
}

Received: June 14, 2016/ Published online: July 25, 2016

(C) The Author(s) 2016. This article is published with open access at Springerlink.com

\begin{abstract}
Introduction: Latanoprostene bunod (LBN) is a novel nitric oxide (NO)-donating prostaglandin F2 $\alpha$ analog. We evaluated the long-term safety and intraocular pressure (IOP)-lowering efficacy of LBN ophthalmic solution $0.024 \%$ over 1 year in Japanese subjects with open-angle glaucoma (OAG) or ocular hypertension (OHT).
\end{abstract}

Methods: This was a single-arm, multicenter, open-label, clinical study. Subjects aged 20 years

Enhanced content To view enhanced content for this article, go to http://www.medengine.com/Redeem/ 83E4F0606B69CADE.

The members of JUPITER Study Group are listed in "Acknowledgments".

K. Kawase $(\bowtie)$

Gifu University Hospital, Gifu, Japan

e-mail: kawase-gif@umin.ac.jp

J. L. Vittitow

Clinical Affairs, Bausch + Lomb, Bridgewater, NJ,

USA

R. N. Weinreb

Department of Ophthalmology and Shiley Eye

Institute, Hamilton Glaucoma Center, University of

California San Diego, La Jolla, CA, USA

M. Araie

Kanto Central Hospital of The Mutual Aid

Association of Public School Teachers, Tokyo, Japan and older with a diagnosis of OAG or OHT instilled 1 drop of LBN ophthalmic solution $0.024 \%$ in the affected eye(s) once daily in the evening for 52 weeks and were evaluated every 4 weeks. Safety assessments included vital signs, comprehensive ophthalmic exams, and treatment-emergent adverse events (AEs). Absolute and percent reductions from baseline in IOP were also determined.

Results: Of 130 subjects enrolled, 121 (93.1\%) completed the study. Mean age was 62.5 years, and mean (standard deviation) baseline IOP was 19.6 (2.9) and 18.7 (2.6) $\mathrm{mmHg}$ in study eyes and treated fellow eyes, respectively. Overall, $76 / 130(58.5 \%)$ and 78/126 (61.9\%) subjects experienced $\geq 1$ AEs in study eyes and treated fellow eyes, respectively. In both study eyes and treated fellow eyes, the most common AEs were conjunctival hyperemia, growth of eyelashes, eye irritation, and eye pain. At 52 weeks, $9 \%$ of treated eyes had an increase in iris pigmentation compared with baseline based on iris photographs. No safety concerns emerged based on vital signs or other ocular assessments. Mean reductions from baseline in IOP of $22.0 \%$ and $19.5 \%$ were achieved by week 4 in study and treated fellow eyes, respectively. 
These reductions were maintained through week $52(P<0.001$ vs. baseline at all visits).

Conclusion: Once daily LBN ophthalmic solution $0.024 \%$ was safe and well-tolerated in Japanese subjects with OAG or OHT when used for up to 1 year. Long-term treatment with LBN ophthalmic solution $\quad 0.024 \%$ provided significant and sustained IOP reduction.

Trial registration: ClinicalTrials.gov identifier, NCT01895972.

Funding: Bausch \& Lomb, Inc. a division of Valeant Pharmaceuticals International Inc.

Keywords: Intraocular pressure; Nitric oxide; Ocular hypertension; Open-angle glaucoma; Ophthalmology; Prostaglandin

\section{INTRODUCTION}

Open-angle glaucoma (OAG) is associated with progressive visual field damage and visual function loss that can lead to disability and adversely affect health-related quality of life [1-4]. Ocular hypertension (OHT) is considered a key risk factor for primary OAG, and reducing intraocular pressure (IOP) and maintaining target IOP can delay or prevent the onset of primary OAG in patients with OHT and slow disease progression in patients with glaucoma [5-10]. Accordingly, recommended goals of treatment for patients with OAG and those with OHT at risk of developing OAG include maintaining IOP within a target range and achieving stability of the optic nerve/retinal nerve fiber layer status and of visual fields $[11,12]$. A desirable IOP range should be determined for each patient based on a goal of minimizing the impact of visual field loss on quality of life; the upper limit of this range is considered the "target pressure" for achieving the sought after clinical goals. Lowering of IOP by $25 \%$ is a well-documented benchmark for slowing the progression of primary OAG, but even more aggressive targets may be appropriate in some patients depending on disease severity and other risk factors [11-13].

Topical prostaglandin analogs are potent ocular hypotensive agents with good IOP-lowering efficacy and a favorable safety profile $[14,15]$. Common ocular side effects of topical prostaglandin receptor agonists include conjunctival hyperemia, elongation and darkening of eyelashes, iris pigmentation changes, and periocular skin hyperpigmentation [16-19]. While these agents are considered first-line interventions for pharmaceutical lowering of IOP in OAG and $\mathrm{OHT}$, it is not uncommon for patients to require add-on therapy to reach target IOP [20].

Latanoprostene bunod (LBN; BOL-303259-X, Bausch \& Lomb, Inc.) is a novel IOP-lowering compound with a dual mechanism of action. Following ocular instillation, LBN is rapidly metabolized into latanoprost acid, a prostaglandin F2 $\alpha$ analog, and butanediol mononitrate, a nitric oxide (NO)-donating moiety, which is subsequently reduced to 1,4 butanediol, an inactive metabolite, and NO (Fig. 1) [21, 22]. Latanoprost reduces IOP primarily by increasing uveoscleral outflow via long-term remodeling of the extracellular matrices in the ciliary body ("nonconventional outflow") [23-28], whereas NO donors appear to induce relaxation of the trabecular meshwork and Schlemm's canal leading to increased aqueous outflow ("conventional outflow") [29, 30]. Preclinical and clinical studies suggest that both active moieties of LBN (latanoprost acid and NO) contribute to its potent IOP-lowering effect $[21,22,29]$. In animal models of OHT or glaucoma, LBN produced significantly greater reductions in IOP than equimolar 


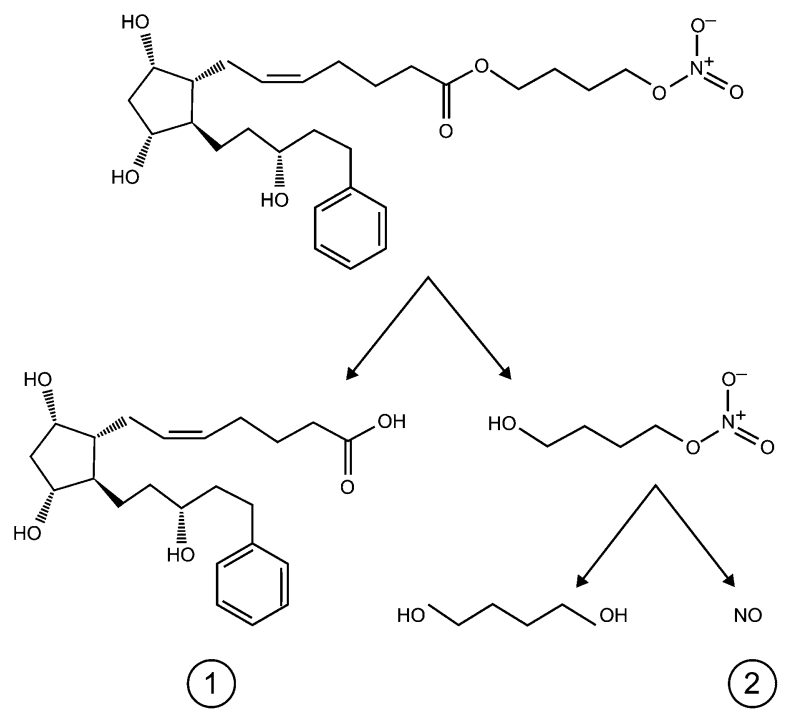

Fig. 1 Metabolism of latanoprostene bunod to latanoprost acid (1) and butanediol mononitrate with subsequent release of nitric oxide (2) and 1,4-butanediol, an inactive metabolite

concentrations of latanoprost [21]. In a study using prostanoid FP-receptor knockout mice, LBN administration lowered IOP from 0.45 to $1.23 \mathrm{mmHg}$, while latanoprost had no effect, providing evidence to support a distinct pharmacologic activity of NO [31]. Clinically, LBN $0.024 \%$ was shown to have a greater IOP-lowering effect compared with latanoprost $0.005 \%$ in a phase 2, randomized, investigator-masked, parallel-group doseranging study in 413 patients with OAG or OHT (the VOYAGER study [22]; ClinicalTrials.gov identifier, NCT01223378). Furthermore, a study comparing the effects of LBN and latanoprost on human trabecular meshwork cell (HTMC) contractility showed that LBN produces significantly greater HTMC relaxation than latanoprost suggesting that increased conventional outflow facility may contribute to the additional IOP-lowering effects of LBN compared with latanoprost $[21,29]$.
A previous single-center, open-label clinical study in healthy Japanese male volunteers (the KRONUS study [32]; ClinicalTrials.gov identifier, NCT01895985) demonstrated that LBN $0.024 \%$ administered once daily (QD) in the evening significantly lowered IOP throughout the day in this population. The current study was designed to evaluate the clinical safety of LBN ophthalmic solution $0.024 \%$ (hereafter referred to as LBN $0.024 \%$ ) over a 1-year treatment period in a Japanese population with OAG or OHT. The ability of LBN $0.024 \%$ to maintain lowered IOP over this time frame was also evaluated.

\section{METHODS}

\section{Study Design}

The JUPITER study (ClinicalTrials.gov identifier, NCT01895972) was a single-arm, open-label, clinical study conducted at 12 investigational sites in Japan between July 5, 2013 and April 2, 2015. The protocol was approved by the Institutional Review Board at each site prior to the initiation of the study. The study was conducted in accordance with Good Clinical Practice, as described in the International Conference on Harmonisation Harmonized Tripartite Guidelines for Good Clinical Practice; the United States Code of Federal Regulations; and the ethical principles in the Declaration of Helsinki. All subjects provided written informed consent before any study-specific procedures were performed. Eligible subjects instilled LBN $0.024 \%$ QD in the evening (approximately $8 \mathrm{PM}$ ) for 52 weeks and were evaluated every 4 weeks. 


\section{Subjects}

The study enrolled males and females, $\geq 20$ years of age, with a diagnosis of OAG (including normal-tension glaucoma [NTG], pigmentary, or pseudoexfoliative glaucoma), or OHT in one or both eyes. Eligible subjects were required to have a mean/median IOP $\geq 15 \mathrm{mmHg}$ and $\leq 36 \mathrm{mmHg}$ at $10 \mathrm{AM}$ in at least 1 eye, and IOP $\leq 36 \mathrm{mmHg}$ in both eyes at Visit 3 (Day 0/baseline), which occurred after a washout period in those subjects on topical hypotensive treatment at the time of enrollment. Eligible subjects also must have had corrected decimal visual acuity (VA) or best-corrected decimal visual acuity (BCVA) $\geq 0.5$ in both eyes and central corneal thickness $\leq 600 \mu \mathrm{m}$.

Subjects were ineligible for study participation if they had participated in another clinical trial within 30 days of Visit 3, or within 30 days of Visit 1 (screening) for subjects requiring a washout period; had a known hypersensitivity or contraindication to any of the ingredients of the study treatments; were unable to discontinue contact lens use or other eye drop mediations (e.g., artificial tears) during and $15 \mathrm{~min}$ after instillation of study drug and during study visits; had any condition that prevented reliable applanation tonometry; had advanced glaucoma (mean deviation $<-12 \mathrm{~dB}$ or split fixation) or other significant ophthalmic disease; or had very narrow angles (three quadrants with less than Grade 2), a history of or current angle closure, or congenital or secondary glaucoma. The study also excluded subjects who required treatment with ocular or systemic corticosteroids, or were in need of or expected to require additional topical or systemic treatment for OAG or OHT, or subjects with an anticipated need to initiate or modify medication known to affect IOP (e.g., $\beta$-adrenergic antagonists, $\alpha$-adrenergic agonists, calcium channel blockers, angiotensinconverting enzyme inhibitors, and angiotensin II receptor blockers) during the study.

\section{Study Treatments and Assessments}

Baseline data were recorded at Visit 1. Subjects undergoing treatment with an IOP-lowering medication were required to undergo a washout period, with the length of the washout dependent on the type of medication used (a minimum of 5 days for miotics and oral/topical carbonic anhydrase inhibitors, 14 days for sympathomimetics, and 28 days for topical prostaglandin analogs, $\beta$-blockers, and combination drugs with $\beta$-blockers). A mid-washout visit (Visit 2) was scheduled for those requiring washout longer than 2 weeks. Any subject with a mean/median IOP exceeding $36 \mathrm{mmHg}$ in either eye at any point during the washout period was withdrawn from the study.

All subjects were assigned to treatment with LBN ophthalmic solution $0.024 \%$ QD. Each subject was instructed to instill one drop in the affected eye(s) QD in the evening (approximately $8 \mathrm{PM}$ ) beginning in the evening of Visit 3 and continuing to the evening before Visit 16 (week 52). The study eye was the eye that qualified per inclusion criteria at Visit 3. If both eyes qualified, then the study eye was the eye with the higher IOP at Visit 3, or the right eye if both eyes had the same IOP. If both eyes of a subject had a diagnosis of OAG or OHT, then both eyes were treated for the duration of the study, even if only one eye qualified at baseline. After the baseline visit, subjects completed a total of 13 visits, with visits occurring every 4 weeks from Visit 4 (week $4 \pm 3$ days) through Visit 16 (week $52 \pm 7$ days). A diary card for recording LBN 
administration was dispensed at baseline and collected at the last study visit.

Safety assessments included treatmentemergent adverse events (AEs), vital signs, corrected decimal VA, conjunctival hyperemia assessment, slit-lamp examination findings, ophthalmoscopy findings, photographs of the irides, eyelids, and eyelashes, visual field assessment, gonioscopy, and pachymetry. VA was measured at baseline and all study visits using a decimal VA chart. The investigator graded conjunctival hyperemia prior to slit-lamp examination and IOP measurement on a scale of 1-4 using photographic standards ( $1=$ none, $4=$ severe). Photographs were taken using a slit-lamp mounted digital camera at Visits 3 (Day 0) and 16 (week 52), and were evaluated at the end of the study to assess any changes. Iris pigmentation was graded using four categories ( $1=$ no increase, $2=$ undecided, $3=$ possible increase, and $4=$ clear increase) by an independent reviewer, whereas any change in eyelid pigmentation or eyelashes was evaluated by the investigator and reported as an $\mathrm{AE}$.

IOP was assessed at screening, the mid-washout visit (if applicable), baseline, and at each post-baseline study visit in both eyes at $10 \mathrm{AM} \pm 30$ min using a Goldman applanation tonometer. For each patient, IOP was measured by the same operator using the same tonometer at each visit whenever possible.

\section{Endpoints}

Efficacy endpoints were absolute IOP values and reduction from baseline (RFB) in IOP. Safety endpoints included AEs, vital signs, corrected decimal VA, conjunctival hyperemia assessment, slit-lamp examination, ophthalmoscopy, photographs, visual field assessment, gonioscopy, and pachymetry.

\section{Statistical Analysis}

The sample size of 130 subjects was not based on power considerations for testing any hypothesis and was assumed to provide sufficient data to study the safety profile of LBN 0.024\% QD over 52 weeks using descriptive statistics.

Treatment adherence was defined as the percentage of prescribed instillations received (based on diary card entries).

Safety analyses were based on the safety population, which included all subjects who received at least one dose of study drug. Treatment-emergent AEs were coded using Medical Dictionary for Regulatory Activities, version 16.0 and summarized by severity and relationship to study drug. Treatment-emergent ocular AEs were summarized for study eyes and treated fellow eyes, and treatment-emergent non-ocular AEs were summarized at the subject level by system organ class and preferred term.

Vital sign measurements and visual acuity were summarized using descriptive statistics. Conjunctival hyperemia was categorized as none, mild, moderate, and severe, with the number and percentage of subjects in each category presented by visit. The number and percentage of subjects having $\geq 1$ hyperemia and $\geq 1$ moderate or severe hyperemia were also presented by visit. Iris photographs from Visits 3 and 16 were evaluated for pigmentation changes. A subject was identified as having a possible or clear increase in iris pigmentation for a given eye if baseline/post-baseline photograph pairs had a final pair grade of 3 or 4 .

Efficacy analyses were based on the safety population (all subjects who received at least 1 dose of study drug). The absolute IOP, RFB in IOP, and mean percent change from week 4 through week 52 were summarized for study 
eyes and treated fellow eyes at each visit using descriptive statistics and discrete summaries (proportion of subjects with RFB in IOP $\geq 5$ and $\geq 10 \mathrm{mmHg}$; proportion of subjects with RFB in IOP at each visit categorized into: $\leq-5$, -4 to $0,1-4,5-9,10-14$, and $\geq 15 \mathrm{mmHg}$ ). In addition, a paired $t$ test was performed on the RFB at each visit.

In general, continuous variables were summarized by sample size, mean, standard deviation (SD), median, minimum, and maximum. Summaries for discrete variables included the tabulation of frequencies and percentages. All statistical analyses were performed using the SAS software (SAS Institute, Cary, NC, USA) version 9.2 or higher.

\section{RESULTS}

\section{Subjects}

A total of 151 subjects were screened. Of these, 130 subjects were enrolled and 121 (93.1\%) completed the study. Reasons for study discontinuation included AEs $(n=4)$, withdrawal of consent $(n=4)$, and investigator decision $(n=1)$.

The mean (SD) age of the study population was 62.5 (18.9) years (range 39-81 years); the median age was 64.0 years. A slightly higher percentage of subjects was female than male $(56.9 \%$ vs. $43.1 \%)$, and all subjects were Japanese. The majority of subjects (90.0\%) were on prior IOP-lowering medication at screening and required a washout. In all but four subjects, both eyes qualified for treatment. Hence, 130 study eyes and 126 fellow eyes qualified for treatment. Mean [SD] corneal thickness at baseline was similar between study eyes (546.1 [31.2] $\mu \mathrm{m})$ and treated fellow eyes $(544.4[31.1] \mu \mathrm{m})$. Mean (SD) baseline IOP was 19.6 (2.9) $\mathrm{mmHg}$ (range $15.0-30.0 \mathrm{mmHg}$ ) for study eyes and 18.7 (2.6) $\mathrm{mmHg}$ (range $14.5-27.0 \mathrm{mmHg}$ ) for treated fellow eyes. The majority of study eyes $(74.6 \%)$ and treated fellow eyes $(85.7 \%)$ and all non-treated fellow eyes had a baseline IOP within 15-21 mmHg; baseline IOP was between 22 and $29 \mathrm{mmHg}$ in $24.6 \%$ of study eyes and $14.3 \%$ of treated fellow eyes. One study eye had a baseline IOP between 30 and $36 \mathrm{mmHg}$. All eyes had brown iris color.

The mean (SD) duration of exposure to LBN ophthalmic solution $0.024 \%$ was 351.5 (59.30) days, and the median (range) duration of exposure was 364.0 (28-371) days. Based on diaries, compliance with dosing instructions was excellent (81-120\% for all subjects).

\section{Safety}

At least 1 ocular AE was reported for 76 (58.5\%) study eyes and 78 (61.9\%) treated fellow eyes (Table 1). Ocular AEs considered treatment-related were reported in a similar percentage $(48 \%)$ of study eyes and treated fellow eyes. The most frequently reported ocular AEs in study eyes and treated fellow eyes were conjunctival hyperemia $(17.7 \%$ and $16.7 \%$, respectively), growth of eyelashes (16.2\% and $16.7 \%)$, eye irritation $(11.5 \%$ and $11.9 \%)$, and eye pain (10.0\% and $10.3 \%)$. Ocular AEs were considered mild to moderate in severity; no severe ocular AEs were reported.

There were four study discontinuations secondary to AEs, including three subjects with serious AEs (malignant lung neoplasm, lung adenocarcinoma, and gastric cancer), and one subject who experienced a non-serious $\mathrm{AE}$ of cataract in the treated fellow eye, none of which were considered related to study treatment.

Overall, 67 (51.5\%) subjects experienced at least 1 non-ocular AE. The most commonly 
Table 1 Incidence of ocular treatment-emergent adverse events occurring in at least $1 \%$ of subjects in the study eye or the treated fellow eye (safety population)

\begin{tabular}{|c|c|c|}
\hline \multirow[t]{2}{*}{ Adverse events } & \multicolumn{2}{|l|}{ LBN $0.024 \%$} \\
\hline & $\begin{array}{l}\text { Study eye } \\
(N=130) n(\%)\end{array}$ & $\begin{array}{l}\text { Treated fellow eye } \\
(N=126) n(\%)\end{array}$ \\
\hline$\geq 1$ ocular $\mathrm{AE}$ & $76(58.5)$ & $78(61.9)$ \\
\hline$\geq 1$ treatment-related ocular $\mathrm{AE}$ & $62(47.7)$ & $61(48.4)$ \\
\hline \multicolumn{3}{|l|}{ Eye disorders } \\
\hline Conjunctival hyperemia $^{a}$ & $23(17.7)$ & $21(16.7)$ \\
\hline Growth of eyelashes & $21(16.2)$ & $21(16.7)$ \\
\hline Eye irritation & $15(11.5)$ & $15(11.9)$ \\
\hline Eye pain & $13(10.0)$ & $13(10.3)$ \\
\hline Iris hyperpigmentation & $5(3.8)$ & $5(4.0)$ \\
\hline Blepharal pigmentation & $4(3.1)$ & $4(3.2)$ \\
\hline Blepharitis & $3(2.3)$ & $3(2.4)$ \\
\hline Eye pruritus & $3(2.3)$ & $3(2.4)$ \\
\hline Asthenopia & $3(2.3)$ & $2(1.6)$ \\
\hline Conjunctival hemorrhage & $2(1.5)$ & $3(2.4)$ \\
\hline Punctate keratitis & $3(2.3)$ & $2(1.6)$ \\
\hline Trichiasis & $3(2.3)$ & $2(1.6)$ \\
\hline Cataract & $1(0.8)$ & $3(2.4)$ \\
\hline Hordeolum & $1(0.8)$ & $3(2.4)$ \\
\hline Foreign body sensation in eyes & $2(1.5)$ & $1(0.8)$ \\
\hline Visual impairment & $1(0.8)$ & $2(1.6)$ \\
\hline Vitreous floaters & $1(0.8)$ & $2(1.6)$ \\
\hline Chalazion & $0(0.0)$ & $2(1.6)$ \\
\hline
\end{tabular}

Treatment-related ocular AEs were those categorized as possibly, probably, or definitely related to treatment $A E$ treatment-emergent adverse event, $L B N$ latanoprostene bunod

${ }^{a}$ Reported as an AE (see Table 2 for investigator assessments of hyperemia)

reported non-ocular AEs included nasopharyngitis (42 [32.3\%] subjects), influenza (5 [3.8\%] subjects), eczema (4 [3.1\%] subjects), and osteoporosis (3 [2.3\%] subjects). All other non-ocular AEs occurred in one or two subjects each. None of the non-ocular AEs were considered related to study drug.
Eight subjects experienced ten non-ocular serious AEs (road traffic accident, fibula fracture, and tibia fracture [all in one subject]; breast cancer; lung adenocarcinoma; large intestine polyp; gallbladder stones; malignant lung neoplasm; gastric cancer; and vestibular neuronitis), three of which (gallbladder stones, 
Table 2 Incidence of conjunctival hyperemia per investigator assessment, by study visit (safety population treated with LBN $0.024 \%)$

\begin{tabular}{lll}
\hline Study visit & \multicolumn{2}{l}{$\begin{array}{l}\text { Any hyperemia/moderate hyperemia } \\
\text { Eyes, } \boldsymbol{n}(\%)\end{array}$} \\
\cline { 2 - 3 } & Study eye $(\boldsymbol{N}=\mathbf{1 3 0})^{\mathbf{b}}$ & Treated fellow eye $(\boldsymbol{N}=\mathbf{1 2 6})^{\mathbf{b}}$ \\
\hline Baseline & $20(15.4) / 0(0.0)$ & $18(14.3) / 0(0.0)$ \\
Week 4 & $27(20.8) / 0(0.0)$ & $24(19.0) / 0(0.0)$ \\
Week 8 & $26(20.2) / 0(0.0)$ & $24(19.2) / 0(0.0)$ \\
Week 12 & $24(18.8) / 2(1.6)$ & $22(17.7) / 2(1.6)$ \\
Week 16 & $24(19.0) / 1(0.8)$ & $21(17.2) / 1(0.8)$ \\
Week 20 & $25(19.8) / 1(0.8)$ & $22(18.0) / 1(0.8)$ \\
Week 24 & $25(19.8) / 1(0.8)$ & $22(18.0) / 1(0.8)$ \\
Week 28 & $22(17.5) / 1(0.8)$ & $22(18.0) / 2(1.6)$ \\
Week 32 & $23(18.4) / 1(0.8)$ & $22(18.2) / 1(0.8)$ \\
Week 36 & $22(17.9) / 1(0.8)$ & $20(16.8) / 1(0.8)$ \\
Week 40 & $22(18.0) / 1(0.8)$ & $20(16.9) / 1(0.8)$ \\
Week 44 & $23(18.9) / 1(0.8)$ & $20(16.9) / 1(0.8)$ \\
Week 48 & $22(18.0) / 1(0.8)$ & $20(16.9) / 1(0.8)$ \\
Week 52 & $22(18.2) / 1(0.8)$ & $20(17.1) / 1(0.9)$ \\
\hline
\end{tabular}

LBN latanoprostene bunod

a There were no instances of severe hyperemia in any treated eye during the study

b Data missing for the study eye and the treated fellow eye for one subject at week 8; two subjects at week 12; four subjects at weeks 16,20,24, and 28; five subjects at week 32; seven subjects at week 36; eight subjects at weeks 40, 44, and 48; and nine subjects at week 52

large intestine polyp, breast cancer) were classified after the subject ended study participation. The serious $\mathrm{AE}$ of vestibular neuronitis was considered severe in intensity, whereas all other serious AEs were considered mild or moderate in severity. None of the serious AEs were considered by the investigator to be related to study treatment.

No treatment-related changes in blood pressure or heart rate were observed from baseline through week 52. Two subjects had vital sign measurements that were associated with AEs (mild hypertension) considered to be not or unlikely related to study drug.
Mean decimal VA at baseline was 1.11 in the study eye and 1.13 in the treated fellow eye. For all post-baseline study visits, the mean decimal VA ranged from 1.10 to 1.13 for the study eye and 1.10-1.15 for the treated fellow eye.

The incidence of conjunctival hyperemia as assessed by investigators is summarized in Table 2 by visit and severity. At baseline, prior to treatment, mild hyperemia was present in 20 (15.4\%) study eyes and 18 (14.3\%) treated fellow eyes. At the week 4 and week 8 visits, mild hyperemia was noted in additional 6 or 7 eyes in each group. The proportion of eyes with hyperemia remained low; at the 52 week visit, 
the number of eyes with hyperemia was only 2 higher than at baseline in both the study eye and treated fellow eye groups. From week 12 on, there were 1 or 2 eyes in each group with moderate hyperemia; all other cases were mild. No subjects had severe conjunctival hyperemia at any visit during the study.

Abnormal biomicroscopy findings for the lid, conjunctiva bulbi, the conjunctiva palpebrae, the cornea, and the anterior chamber were rare in both study eyes and treated fellow eyes and showed no consistent patterns. The number of eyes with abnormal findings for these assessments either stayed the same or increased or decreased by 1 or 2 subjects at each study visit. The number of study and treated fellow eyes with abnormal iris findings showed a gradual increase starting at week 20 . Other ocular assessments (anterior chamber cells, anterior flare, posterior synechiae, anterior vitreous haze, and number of subjects with an open or absent posterior lens capsule) were unremarkable.

Based on the analysis of iris photographs taken at week 52 in comparison with those taken at baseline, $10.0 \%(13 / 130)$ of study eyes and $8.8 \%$ of $(11 / 125)$ of treated fellow eyes were judged as having a clear iris pigmentation increase from baseline; and an additional $14.6 \%(19 / 130)$ of study eyes and 13.6\% (17/ $125)$ of treated fellow eyes were judged as having a possible iris pigmentation increase from baseline.

Ophthalmoscopy findings indicated no changes in the number of subjects with abnormalities in the vitreous body, the retina, the macula, the choroid, the optic nerve, or the mean cup/disc vertical ratio in the study eye or the treated fellow eye after 52 weeks of treatment with LBN $0.024 \%$. At baseline, optic disc hemorrhage was evident in one study eye and two treated fellow eyes; at week 4, the presence of optic disc hemorrhage was unchanged among study eyes and decreased by one subject at week 4 in treated fellow eyes. Missing assessments precluded evaluation of optic disc hemorrhage at subsequent visits. At baseline, rim loss was noted in 19 (14.6\%) of study eyes and 13 (10.3\%) of treated fellow eyes, and retinal nerve fiber layer defects were observed in $13(10.0 \%)$ of study eyes and 6 $(4.8 \%)$ of treated fellow eyes. There were no changes in the number of eyes with these findings at any study visit, and no notable results from visual field assessment, gonioscopy, or pachymetry.

\section{Efficacy}

The mean (SD) IOP at each visit from baseline to week 52 for the study eye and the treated fellow eye for all subjects is shown in Fig. 2, and the RFB in IOP from baseline to each study visit is shown in Fig. 3. In the study eye, a $22.0 \%$ reduction in IOP to 15.3 (3.0) $\mathrm{mmHg}$ was achieved by week 4 , and reductions greater than $22 \%$ were observed at every subsequent visit. Similarly, a $19.5 \%$ reduction in IOP to 15.0 (2.8) $\mathrm{mmHg}$ was achieved by week 4 in the treated fellow eye, and reductions of more than $20 \%$ were seen at every visit after week 4 . At week 52, the percent reductions in IOP were $26.3 \%$ and $23.0 \%$ in study eyes and treated fellow eyes, respectively, to 14.4 (2.7) $\mathrm{mmHg}$ in both eyes. For both the study eye and the treated fellow eye, the reductions from baseline were statistically significant $(P<0.001)$ at every study visit from week 4 through week 52 .

At weeks 4 and $8,42.3 \%$ and $48.1 \%$, respectively, of subjects had an RFB in IOP of $\geq 5 \mathrm{mmHg}$ for the study eye. Between $52.3 \%$ and $64.2 \%$ of subjects had a reduction in IOP of $\geq 5 \mathrm{mmHg}$ for the study eye from week 12 to week 52 . From weeks 8 to 20, between $42.4 \%$ 


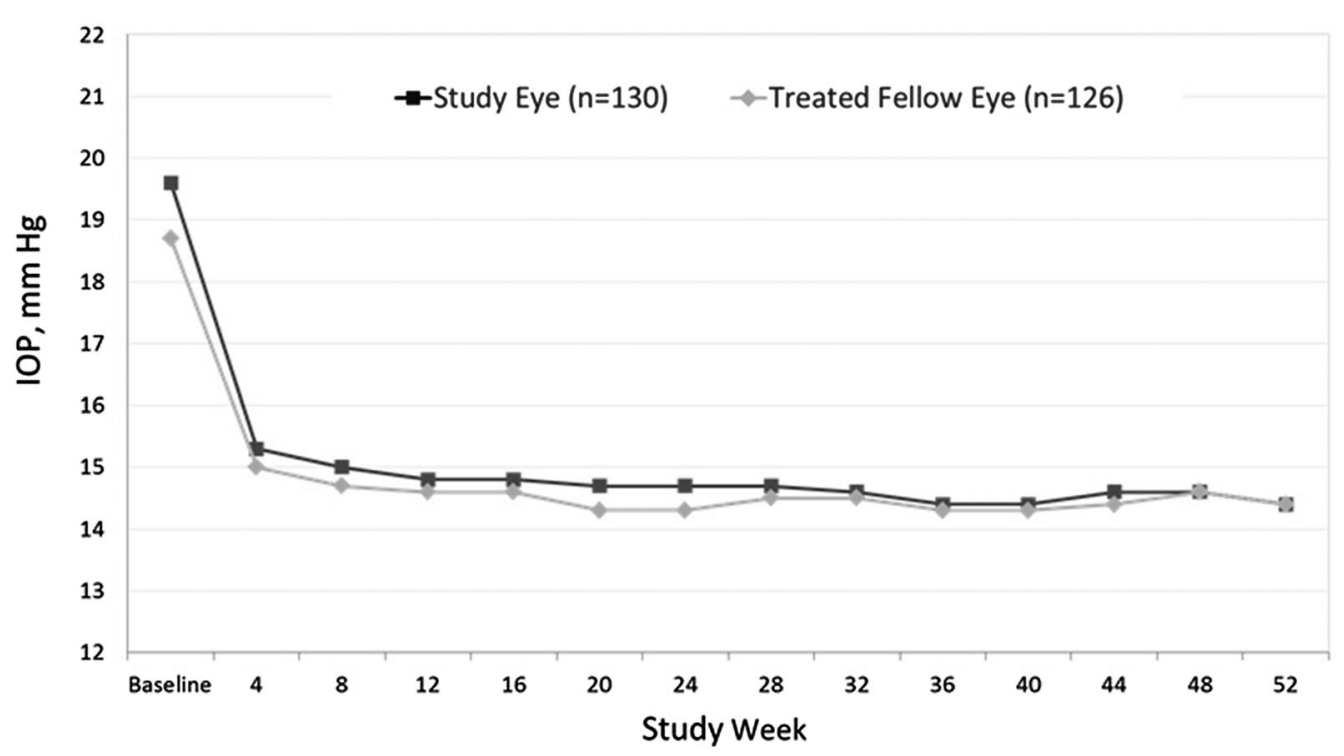

Fig. 2 Mean IOP $(\mathrm{mmHg})$ at each study visit in the study eye and the treated fellow eye (safety population). All post-baseline measurements $P<0.001$ vs. baseline.
Standard deviations at each timepoint ranged from 2.31 to $3.00 \mathrm{mmHg}$. IOP intraocular pressure

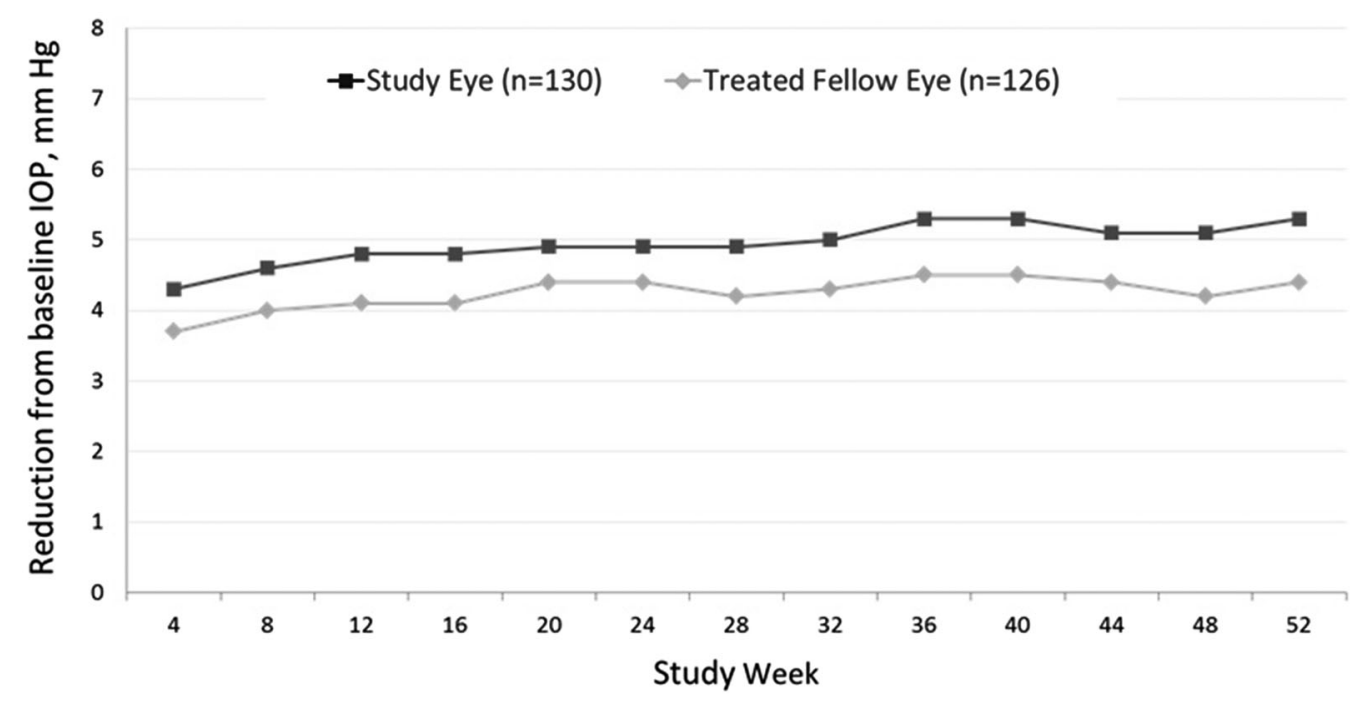

Fig. 3 Reduction from baseline in mean IOP $(\mathrm{mmHg})$ by visit (safety population). All data points $P<0.001$ for reduction from baseline. Standard deviations at each timepoint ranged from 2.61 to $2.88 \mathrm{mmHg}$. IOP intraocular pressure

and $47.5 \%$ of subjects had a reduction in IOP of $\geq 5 \mathrm{mmHg}$ in the treated fellow eye. Reductions in IOP of $\geq 5 \mathrm{mmHg}$ were observed in the treated fellow eye for $50.0-54.2 \%$ of subjects at weeks 24 and 28 and weeks 36-48, whereas at week $52,48.7 \%$ of subjects had a reduction in IOP of $\geq 5 \mathrm{mmHg}$ in the treated fellow eye.

\section{DISCUSSION}

This multicenter, open-label study in Japanese subjects with OAG or OHT was designed to evaluate the long-term safety and IOP-lowering efficacy of LBN ophthalmic solution $0.24 \%$ QD. The study treatment duration of 12 months is 
the longest reported with LBN $0.024 \%$ to date, and adds to a growing body of clinical data with this novel compound [22, 32-35]. Safety was assessed regularly throughout the study using a comprehensive battery of prospective ocular and non-ocular clinical evaluations along with $\mathrm{AE}$ monitoring. The combined findings of the safety evaluations confirmed the long-term safety and tolerability of LBN $0.024 \%$. Over the one-year treatment period, there were no discontinuations due to AEs. The most common AEs were cosmetic and typical of topical prostaglandin analog use [36, 37], including conjunctival hyperemia and eyelash growth. Conjunctival hyperemia, mostly mild, was reported as an $\mathrm{AE}$ in $17-18 \%$ of treated eyes and was consistent with the rates of hyperemia determined by proactive investigator assessments at each study visit using photographic standards (range 17-20\% of treated eyes). It should be noted that investigator-identified hyperemia was present before treatment initiation in about one of every six eyes. After the first 4 weeks of LBN treatment, the prevalence of investigator-identified hyperemia increased to 1 out of every five eyes, but remained generally stable, even showing a slight decline over the remaining 48 weeks. Iris hyperpigmentation is another well-recognized side effect of topical prostaglandin analogs $[18,38]$ with apparently cosmetic-only implications, based on current understanding $[19,39]$. In the current study, iris hyperpigmentation was reported as an $\mathrm{AE}$ in $4 \%$ of treated eyes, and, at 1 year, an increase in iris pigmentation was noted in $9 \%$ of treated eyes and a possible increase was noted in another $14 \%$ based on iris photographs. Iridial pigmentation changes have also been reported with latanoprost in clinical studies with Japanese subjects [40-43]. These studies found the incidence of iris pigmentation to increase in proportion to duration of latanoprost treatment, with reported frequencies at 1 year ranging from 51.6\% [42] to 58.2\% [43] based on slit-lamp biomicroscopy, a rate much higher than that found in the current study with LBN. However, another 1-year study of latanoprost in 124 Japanese patients with primary OAG or OHT reported iris hyperpigmentation in only ten patients [44].

Reducing IOP is the primary modifiable factor in managing patients with, or at risk for, glaucoma. Expert consensus guidelines suggest that gold standard pharmacologic glaucoma therapy is defined by the long-term control of IOP with no induction of tachyphylaxis or tolerance [45]. Tachyphylaxis, or diminished responsiveness to therapy over time, necessitates therapy modification, often in the form of adjunctive IOP-lowering agents $[20,46]$ which can increase treatment costs and lessen adherence in some patients [47]. Thus, the ideal treatment paradigm would be a monotherapy regimen that is simple to use, with good tolerability and sustained IOP-lowering activity over time.

Most long-term, prospective clinical research studies with prostaglandin analogs have described effective and sustained IOP-lowering over multi-year treatment periods with no apparent tachyphylaxis [48-52]. However, a number of studies based on claims data and reflective of "real world" experience suggest that up to one-half of patients started on prostaglandin analog monotherapy require adjunctive IOP-lowering medication within 2 years $[20,53]$. It remains to be investigated whether the dual mechanism of action of LBN will translate to practical clinical benefits, including a reduced need for adjunctive therapy over time, whether due to sustained efficacy or improved patient adherence. 
In the current study, significant IOP reduction with LBN treatment was observed quickly, evidenced by a mean reduction of $4.3 \mathrm{mmHg}$ or $22 \%$ from baseline in study eye IOP at week 4 . The IOP-lowering effect was sustained over the entire 52 weeks of the study, and appeared to show a trend suggestive of continued, progressive lowering over the 1-year study period. At 52 weeks, the mean reduction in IOP was $5.3 \mathrm{mmHg}$ or greater than $25 \%$ from baseline in the study eye, which corresponds with the degree of IOP reduction shown to minimize disease severity or progression in OAG [5-9]. Garway-Heath et al. [10] recently published findings from the United Kingdom Glaucoma Treatment Study (UKGTS; Controlled-trials.com identifier, ISRCTN96423140) demonstrating not only IOP lowering, but also clinical benefits in the form of visual field preservation with the use of latanoprost therapy compared with placebo in patients with OAG. Mean IOP reduction in the UKGTS was $3.8 \mathrm{mmHg}$ in patients treated with latanoprost, compared with $0.9 \mathrm{mmHg}$ in the placebo group. In our study, the mean IOP reduction with LBN $0.024 \%$ was typically between 4 and $5 \mathrm{mmHg}$ at each study visit. Of note, there were also no apparent visual field changes after 1 year of treatment with LBN $0.024 \%$, nor were there any changes in safety parameters that could be indicative of glaucoma progression (i.e., optic nerve changes, mean cup/disc vertical ratio, and rim loss).

Japanese populations are known to have lower IOPs compared with non-Asian groups, and NTG is a common finding [54]. The current study population included subjects with NTG, and the majority of eyes had a baseline IOP between 15 and $21 \mathrm{mmHg}$. As in high-pressure glaucoma, the reduction of IOP has been shown to slow visual field damage in NTG $[9,55]$ and may minimize progression of the disease [56-58]. A prior study of
LBN $0.024 \%$ in healthy male Japanese volunteers demonstrated a robust $27 \%$ reduction in IOP after 2 weeks of treatment, despite a mean baseline IOP of $13.6 \mathrm{mmHg}$ in the study group [32]. Other prostaglandin analogs have shown IOP-lowering efficacy in the short-term studies conducted in subjects with NTG [59-62]. Further studies of LBN $0.024 \%$ in patients with NTG are, therefore, warranted given the positive findings of the current study in Japanese subjects. Interestingly, even though most subjects in the current study had a baseline IOP $\leq 21 \mathrm{mmHg}$, LBN produced an IOP reduction similar to that reported in a previous open-label study of latanoprost $0.005 \%$ in Japanese subjects with OAG or OHT which excluded subjects with baseline IOP $\leq 20 \mathrm{mmHg}$ and thus had higher baseline IOPs (mean, 23.5 [2.2] $\mathrm{mmHg}$ ) [44]. The mean (SD) IOP reduction at week 52 in the latter study was 5.4 (2.9) $\mathrm{mmHg}$ from 23.5 (2.2) $\mathrm{mmHg}$ at baseline [44].

Although findings of this study suggest a promising role for LBN in the long-term management of patients requiring IOP reduction, interpretation of the results is limited by the open-label design and lack of an active comparator. However, LBN administered QD in the evening has been evaluated in two large randomized clinical studies of primarily non-Asian patients with OAG or OHT (the APOLLO [33] and LUNAR [35] studies; ClinicalTrials.gov identifiers, NCT01749904 and NCT01749930, respectively) of long duration. Each of these studies consisted of a 3-month double-masked efficacy phase in which subjects were randomized to either LBN QD in the evening or timolol instilled twice daily followed by an open-label safety extension phase lasting up to 1 year in which all subjects received LBN $0.024 \%$. In both studies, LBN was associated with significantly greater diurnal IOP reductions compared with timolol over the 
3-months of double-masked treatment [33, 35].

Furthermore, the IOP lowering with LBN was maintained through the open-label phase of these studies [63].

\section{CONCLUSION}

The results of this single-arm, multicenter, open-label, clinical study suggest that LBN ophthalmic solution $0.024 \%$ QD was safe and well-tolerated, with no significant AEs in Japanese subjects when used for up to 1 year. In addition, the results demonstrated that the long-term treatment with $\mathrm{LBN}$ ophthalmic solution $0.024 \%$ provided significant and sustained reduction of IOP in Japanese subjects with a diagnosis of OAG or OHT.

\section{ACKNOWLEDGMENTS}

Sponsorship, article processing charges, and the open access charge for this study were funded by Bausch \& Lomb, Inc. a division of Valeant Pharmaceuticals International Inc. All named authors meet the International Committee of Medical Journal Editors (ICMJE) criteria for authorship for this manuscript, take responsibility for the integrity of the work as a whole, and have given final approval to the version to be published. All authors had full access to all the data in this study and take complete responsibility for the integrity of the data and accuracy of the data analysis. Editorial assistance was provided by Churchill Communications (Maplewood, NJ) and funded by Bausch \& Lomb, Inc.

The JUPITER Study Group investigators included: Shigeru Hoshiai (Saitama), Setsuko Hashida (Tokyo), Miki Iwasaki (Tokyo), Kiyoshi Kano (Osaka), Kazuhide Kawase (Gifu), Takuji
Kato (Tokyo), Yasuaki Kuwayama (Osaka), Tomoyuki Muramatsu (Shizuoka), Masatada Mitsuhashi (Chiba), Sakae Matsuzaki (Tokyo), Toru Nakajima (Shizuoka), Isao Sato (Tokyo), and Yuzuru Yoshimura (Shizuoka).

Disclosures. Kazuhide Kawase has no conflicts of interest to declare relative to this work. Makoto Araie is a paid consultant for Bausch \& Lomb, Inc. Jason Vittitow is an employee of Bausch \& Lomb, Inc. Robert N. Weinreb has served as a paid consultant for Bausch \& Lomb, Inc., Alcon, and Allergan, and has received grants from Genentech, Heidelberg Engineering, Quark, Nidek, National Eye Institute, Aerie, Topcon, and Aquesys.

Compliance with Ethics Guidelines. The protocol was approved by the Institutional Review Board at each site prior to initiation of the study. The study was conducted in accordance with Good Clinical Practice, as described in the International Conference on Harmonisation Harmonized Tripartite Guidelines for Good Clinical Practice; the United States Code of Federal Regulations; and the ethical principles in the Declaration of Helsinki. All subjects provided written informed consent before any study-specific procedures were performed.

Open Access. This article is distributed under the terms of the Creative Commons Attribution-NonCommercial 4.0 International License (http://creativecommons.org/licenses/ by-nc/4.0/), which permits any noncommercial use, distribution, and reproduction in any medium, provided you give appropriate credit to the original author(s) and the source, provide a link to the Creative Commons license, and indicate if changes were made. 


\section{REFERENCES}

1. Broman AT, Quigley HA, West SK, et al. Estimating the rate of progressive visual field damage in those with open-angle glaucoma, from cross-sectional data. Invest Ophthalmol Vis Sci. 2008;49(1):66-76.

2. Heijl A, Bengtsson B, Hyman L, Leske MC. Early manifest glaucoma trial group. Natural history of open-angle glaucoma. Ophthalmology. 2009; 116(12):2271-6.

3. Varma R, Lee PP, Goldberg I, Kotak S. An assessment of the health and economic burdens of glaucoma. Am J Ophthalmol. 2011;152(4):515-22.

4. Medeiros FA, Gracitelli CP, Boer ER, Weinreb RN, Zangwill LM, Rosen PN. Longitudinal changes in quality of life and rates of progressive visual field loss in glaucoma patients. Ophthalmology. 2015;122(2):293-301.

5. Heijl A, Leske MC, Bengtsson B, et al. Reduction of intraocular pressure and glaucoma progression: results from the early manifest glaucoma trial. Arch Ophthalmol. 2002;120:1268-79.

6. Investigators AGIS. The Advanced Glaucoma Intervention Study (AGIS): 7. The relationship between control of intraocular pressure and visual field deterioration. Am J Ophthalmol. 2000;130:429-40.

7. Lichter PR, Musch DC, Gillespie BW, et al. Interim clinical outcomes in the Collaborative Initial Glaucoma Treatment Study comparing initial treatment randomized to medications or surgery. Ophthalmology. 2001;108:1943-53.

8. Leske MC, Heijl A, Hussein M, et al. Factors for glaucoma progression and the effect of treatment: the early manifest glaucoma trial. Arch Ophthalmol. 2003;121:48-56.

9. Collaborative Normal-Tension Glaucoma Study Group. Comparison of glaucomatous progression between untreated patients with normal-tension glaucoma and patients with therapeutically reduced intraocular pressures. Am J Ophthalmol. 1998;126:487-97.

10. Garway-Heath DF, Crabb DP, Bunce C, et al. Latanoprost for open-angle glaucoma (UKGTS): a randomized, multicenter, placebo-controlled trial. Lancet. 2015;385:1295-304.

11. American Academy of Ophthalmology. Preferred Practice Pattern. Primary open-angle glaucoma. 2015. http://www.aaojournal.org/content/preferredpractice-pattern. Accessed 22 Feb 2016.
12. The Japan Glaucoma Society Guidelines for Glaucoma (3rd Edition). Nippon Ganka Gakkai zasshi 2012;116(1):3-46.

13. Medeiros FA, Susanna R, Singh K. Who should be treated. In: Weinreb RN, Araie M, Susanna R, Goldberg I, Migdal C, Liebmann J, editors. Medical treatment of glaucoma: WGA consensus series 7. Kugler, Amsterdam:The Netherlands; 2010.

14. Schmidl D, Schmetterer L, Garhöfer G, Popa-Cherecheanu A. Pharmacotherapy of glaucoma. J Ocul Pharmacol Ther. 2015;31:63-77.

15. Denis P, Lafuma A, Khoshnood B, Mimaud V, Berdeaux G. A meta-analysis of topical prostaglandin analogues intra-ocular pressure lowering in glaucoma therapy. Curr Med Res Opin. 2007;23(3):601-8.

16. Camras CB, Schumer RA, Marsk A, et al. Intraocular pressure reduction with PhXA34, a new prostaglandin analogue, in patients with ocular hypertension. Arch Ophthalmol. 1992;110(12): 1733-8.

17. Camras CB. Comparison of latanoprost and timolol in patients with ocular hypertension and glaucoma: a six-month masked, multicenter trial in the United States. The United States Latanoprost Study Group. Ophthalmology. 1996;103(1):138-47.

18. Alm A, Schoenfelder J, McDermott J. A 5-year, multicenter, open-label, safety study of adjunctive latanoprost therapy for glaucoma. Arch Ophthalmol. 2004;122(7):957-65.

19. Alm A. Latanoprost in the treatment of glaucoma. Clin Ophthalmol. 2014;8:1967-85.

20. Schmier JK, Hulme-Lowe CK, Covert DW. Adjunctive therapy patterns in glaucoma patients using prostaglandin analogs. Clin Ophthalmol. 2014;10(8):1097-104.

21. Krauss AH, Impagnatiello F, Toris CB, et al. Ocular hypotensive activity of BOL-303259-X, a nitric oxide donating prostaglandin F2 $\alpha$ agonist, in preclinical models. Exp Eye Res. 2011;93(3):250-5.

22. Weinreb RN, Ong T, Scassellati Sforzolini B, et al. A randomised, controlled comparison of latanoprostene bunod and latanoprost $0.005 \%$ in the treatment of ocular hypertension and open angle glaucoma: the VOYAGER study. $\mathrm{Br} J$ Ophthalmol. 2015;99(6):738-45.

23. Lütjen-Drecoll E, Tamm E. Morphological study of the anterior segment of cynomolgus monkey eyes following treatment with prostaglandin F2a. Exp Eye Res. 1988;47:761-9. 
24. Gabelt BT, Kaufman PL. Prostaglandin F2 alpha increases uveoscleral outflow in the cynomolgus monkey. Exp Eye Res. 1989;49:389-402.

25. Nilsson SF, Samuelsson M, Bill A, Stjernschantz J. Increased uveoscleral outflow as a possible mechanism of ocular hypotension caused by prostaglandin F2 alpha-1-isopropylester in the cynomolgus monkey. Exp Eye Res. 1989;48:707-16.

26. Toris CB, Camras CB, Yablonski ME. Effects of PhXA41, a new prostaglandin F2 alpha analog, on aqueous humor dynamics in human eyes. Ophthalmology. 1993;100(9):1297-304.

27. Lindsey JD, Kashiwagi K, Kashiwagi F, Weinreb RN. Prostaglandins alter extracellular matrix adjacent to human ciliary muscle cells in vitro. Invest Ophthalmol Vis Sci. 1997;38:2214-23.

28. Richter M, Krauss AH, Woodward DF, Lütjen-Drecoll E. Morphological changes in the anterior eye segment after long-term treatment with different receptor selective prostaglandin agonists and a prostamide. Invest Ophthalmol Vis Sci. 2003;44:4419-26.

29. Cavet ME, Vollmer TR, Harrington KL, VanDerMeid $\mathrm{K}$, Richardson ME. Regulation of endothelin-1-induced trabecular meshwork cell contractility by latanoprostene bunod. Invest Ophthalmol Vis Sci. 2015;56(6):4108-16.

30. Wiederholt M, Sturm A, Lepple-Wienhues A. Relaxation of trabecular meshwork and ciliary muscle by release of nitric oxide. Invest Ophthalmol Vis Sci. 1994;35:2515-20.

31. Saeki T, Tsuruga $H$, Aihara M, Rittenhouse K. Dose-response profile of PF-03187207 (PF-207) and peak IOP lowering response following single topical administration to FP receptor knockout mice vs. wild type mice. Invest Ophthalmol Vis Sci. 2009;50:E-abstract 4064. http://iovs.arvojournals. org/article. aspx ?articleid $=2366444 \&$ resultClick=1. Accessed 22 Feb 2016.

32. Araie M, Sforzolini BS, Vittitow J, Weinreb RN. Evaluation of the effect of latanoprostene bunod ophthalmic solution, $0.024 \%$ in lowering intraocular pressure over $24 \mathrm{~h}$ in healthy Japanese subjects. Adv Ther. 2015;32(11):1128-39.

33. Weinreb RN, Sforzolini BS, Vittitow J, Liebmann J. Latanoprostene bunod $0.024 \%$ vs timolol maleate $0.5 \%$ in the treatment of open-angle glaucoma or ocular hypertension: the APOLLO study. Ophthalmology. 2016;123(5):965-73.

34. Liu JHK, Slight JR, Vittitow JL, et al. Efficacy of latanoprostene bunod $0.024 \%$ compared with timolol $0.5 \%$ in lowering intraocular pressure over
24 hours. Am J Ophthalmol. 2016 (Epub ahead of print).

35. Medeiros FA, Martin KR, Peace J, et al. Comparison of Latanoprostene bunod $0.024 \%$ and timolol maleate $0.5 \%$ in open-angle glaucoma or ocular hypertension: the LUNAR study. Am J Ophthalmol. 2016;. doi:10.1016/j.ajo.2016.05.012 (Epub ahead of print).

36. Schuman JS. Short- and long-term safety of glaucoma drugs. Expert Opin Drug Saf. 2002;1:181-94.

37. Feldman RM. Conjunctival hyperemia and the use of topical prostaglandins in glaucoma and ocular hypertension. J Ocul Pharmacol Ther. 2003;19:23-35.

38. Teus MA, Arranz-Marquez E, Lucea-Suescun P. Incidence of iris colour change in latanoprost treated eyes. Br J Opthalmol. 2002;86:1085-8.

39. Tressler CS, Wiseman RL, Dombi TM, et al. Lack of evidence for a link between latanoprost use and malignant melanoma: an analysis of safety databases and a review of the literature. $\mathrm{Br} \mathrm{J}$ Ophthalmol. 2011;95:1490-5.

40. Chiba T, Kashiwagi K, Chiba N, et al. Comparison of iridial pigmentation between latanoprost and isopropyl unoprostone: a long term prospective comparative study. $\mathrm{Br} \mathrm{J}$ Ophthalmol. 2003;87(8):956-9.

41. Chiba T, Kashiwagi $\mathrm{K}$, Ishijima $\mathrm{K}$, et al. A prospective study of iridial pigmentation and eyelash changes due to ophthalmic treatment with latanoprost. Jpn J Ophthalmol. 2004;48(2):141-7.

42. Hara $T$. Increased iris pigmentation after use of latanoprost in Japanese brown eyes. Nippon Ganka Gakkai Zasshi. 2001;105(5):314-21.

43. Latanoprost-Induced Iris Pigmentation Study Group. Incidence of a latanoprost-induced increase in iris pigmentation in Japanese eyes. Jpn J Ophthalmol. 2006;50(2):96-9.

44. Suzuki M, Mishima HK, Masuda K, Araie M, Kitazawa Y, Azuma I. Efficacy and safety of latanoprost eye drops for glaucoma treatment: a 1-year study in Japan. Jpn J Ophthalmol. 2000;44:33-8.

45. Obstbaum SA, Cioffi GA, Krieglstein GK, et al. Gold standard medical therapy for glaucoma: defining the criteria identifying measures for an evidence-based analysis. Clin Ther. 2004;26(12):2102-20.

46. Kass MA, Heuer DK, Higginbotham EJ, et al. The ocular hypertension treatment study: a randomized 
trial determines that topical hypotensive medication delays or prevents the onset of primary open angle glaucoma. Arch Ophthalmol. 2002;120:701-3.

47. Robin AL, Covert D. Does adjunctive glaucoma therapy affect adherence to the initial primary therapy? Ophthalmology. 2005;112(5):863-8.

48. Bayer A, Weiler W, Oeverhaus U, Skrotzki FE, Stewart WC, Xplore Observation Group. Two-year follow-up of latanoprost $0.005 \%$ monotherapy after changing from previous glaucoma therapies. J Ocul Pharmacol Ther. 2004;20(6):470-8.

49. Hedman K, Watson PG, Alm A. The effect of latanoprost on intraocular pressure during 2 years of treatment. Surv Ophthalmol. 2002;47(Suppl 1):S65-76.

50. Watson PG. Latanoprost. Two years' experience of its use in the United Kingdom. Latanoprost Study Group. Ophthalmology. 1998;105(1):82-7.

51. Tomita G, Araie M, Kitazawa Y, Tsukahara S. A three-year prospective, randomized and open comparison between latanoprost and timolol in Japanese normal-tension glaucoma patients. Eye (Lond). 2004;18(10):984-9.

52. Riva I, Katsanos A, Floriani I, et al. Long-term 24-hour intraocular pressure control with travoprost monotherapy in patients with primary open-angle glaucoma. J Glaucoma. 2014;23(8):535-40.

53. Schmier JK, Lau EC, Covet DW. Two-year treatment patterns and costs in glaucoma patients initiating treatment with prostaglandin analogs. Clin Ophthalmol. 2010;4:1137-43.

54. Sheleg T. Normal-tension (low-tension) glaucoma, glaucoma-basic and clinical concepts. Dr. Shimon Rumelt (ed). ISBN:978-953-307-591-4. InTech. http://www.intechopen.com/download/pdf/23840. Accessed 20 Feb 2016.

55. Anderson DR. Collaborative normal tension glaucoma study. Curr Opin Ophthalmol. 2003;14(2):86-90.
56. Koseki N, Araie M, Shirato S, Yamamoto S. Effect of trabeculectomy on visual field performance in central 30 degrees field in progressive normal-tension glaucoma. Ophthalmology. 1997;104(2):197-201.

57. Shigeeda T, Tomidokoro A, Araie M, Koseki N, Yamamoto S. Long-term follow-up of visual field progression after trabeculectomy in progressive normal-tension glaucoma. Ophthalmology. 2002;109(4):766-70.

58. Kim M, Kim DM, Park KH, Kim TW, Jeoung JW, Kim SH. Intraocular pressure reduction with topical medications and progression of normal-tension glaucoma: a 12-year mean follow-up study. Acta Ophthalmol. 2013;91(4):e270-5.

59. Liu CJ, Ko YC, Cheng CY, et al. Changes in intraocular pressure and ocular perfusion pressure after latanoprost $0.005 \%$ or brimonidine tartrate $0.2 \%$ in normal-tension glaucoma patients. Ophthalmology. 2002;109(12):2241-7.

60. McKibbin M, Menage MJ. The effect of once-daily latanoprost on intraocular pressure and pulsatile ocular blood flow in normal tension glaucoma. Eye (Lond). 1999;13(Pt 1):31-4.

61. Quaranta L, Pizzolante T, Riva I, Haidich AB, Konstas AG, Stewart WC. Twenty-four-hour intraocular pressure and blood pressure levels with bimatoprost versus latanoprost in patients with normal-tension glaucoma. $\mathrm{Br} \mathrm{J}$ Ophthalmol. 2008;92(9):1227-31.

62. Tsumura $\mathrm{T}$, Yoshikawa $\mathrm{K}$, Suzumura $\mathrm{H}$, et al. Bimatoprost ophthalmic solution 0.03\% lowered intraocular pressure of normal-tension glaucoma with minimal adverse events. Clin Ophthalmol. 2012;6:1547-52.

63. Vittitow JL, Liebmann JM, Kaufman PL, et al. Long-term efficacy and safety of latanoprostene bunod $0.024 \%$ for intraocular pressure lowering in patients with open-angle glaucoma or ocular hypertension: APOLLO and LUNAR studies. In: Presented at the Association for Research in Vision and Ophthalmology (ARVO) meeting, Seattle, WA, May 1-5, 2016. 